\title{
Cyclone Amphan: oceanic conditions pre- and post-cyclone using in situ and satellite observations
}

\author{
Suchandra A. Bhowmick ${ }^{1}$, Neeraj Agarwal ${ }^{1}$, Rashmi Sharma ${ }^{1, *}$, R. Sundar ${ }^{2}$, \\ R. Venkatesan', C. Anoopa Prasad and K. N. Navaneeth \\ ${ }^{1}$ Space Applications Centre, Indian Space Research Organization, Ahmedabad 380 015, India \\ ${ }^{2}$ National Institute of Ocean Technology, MOES, Chennai 600 100, India
}

Amphan, a category-5 tropical cyclone, originated over Bay of Bengal (BoB) and had a landfall in West Bengal, India on 20 May, causing havoc in the region. In this study, in-situ buoy and various satellite measurements are used to analyse the ocean condition before and after the storm, primarily from the air-sea interaction perspective. Widespread anomalous warming was observed in BoB before the event, due to high net surface insolation received by the ocean. The warm SST anomalies in the central $B o B$ were coincident with anti-cyclonic warm core eddies, implying availability of higher oceanic heat content. Observations from BD13 buoy, close to the cyclone track showed heating of the overlying atmosphere due to this ocean warming. Strong surface cooling was observed after passage of the cyclone due to wind induced upper-ocean mixing that is stimulated by low stratification in BoB.

Keywords: Air-sea interaction, oceanic conditions, satellite and in situ observations, tropical cyclones.

TROPICAL cyclones (TCs) are the deadliest ocean hazards as they are associated with very strong winds, heavy rainfall and storm surge. Unexpected intensification of cyclones is a serious challenge for disaster management and mitigation. The Indian subcontinent, particularly the coastal regions adjoining the Bay of Bengal $(\mathrm{BoB})$ face the maximum impact of these cyclones which leads to huge loss of life and property. Post Orissa super cyclone in 1999, which resulted in more than 10,000 deaths ${ }^{1}$ several efforts were made to improve the early warning systems supported by real-time satellite imagery and numerical weather prediction models. Generally, in most of the cyclone models, sea surface temperature (SST) has been the only oceanographic input of importance. However, the fact remains that cyclones not only interact with the surface but with the deeper oceans, depending upon the strength of the wind mixing. Thus the energy source through air-sea flux for intensification of the cyc-

\footnotetext{
*For correspondence. (e-mail: rashmi.isro@gmail.com)
}

lones comes from the oceans. Hence, even if atmospheric conditions are favourable, cyclones cannot intensify without sufficient supply of heat flux from the oceans ${ }^{2}$. Complex interaction between atmosphere and ocean is a major player for cyclogenesis and intensification ${ }^{2-5}$. Even in case of the northern Indian Ocean, occurrence of these cyclonic events is remotely modulated by El-Nino and La-Nina events ${ }^{6-8}$. Hence the ongoing research to improve prediction of cyclone track and intensity is a complex problem since many processes related to air-sea interaction are unaccounted in these numerical weather prediction (NWP) models. However, with emerging satellite-based measurements and associated in situ observations from buoy/Argo platforms, it is now easier to examine the ocean processes and air-sea interaction processes that silently act as a stimulus to the origin and intensification of cyclones. With the development of the Indian Ocean network of buoy systems ${ }^{9}$ the cyclone track forecasting models have started assimilating these observations resulting in significant improvement in the prediction of track and intensity of the cyclone.

In this study, the satellite and in situ observations are explored to analyse the pre- and post-cyclone oceanic conditions and to understand the associated air-sea interaction processes during the recent cyclone Amphan. It was a category- $4 \mathrm{TC}$, which formed over BoB on 16 May 2020 and had a landfall at Bakkhali, West Bengal, India, causing destruction in the region on 20th May 2020. The observations from buoys and satellite measurements from INSAT-3D, Scatsat-1, global altimeters and radiometers have been utilized in this study.

\section{Cyclone Amphan}

The TC, Amphan originated over BoB on 16 May 2020. It is the strongest cyclone to hit West Bengal after Sidr of 2007 and can be tagged as the successor of the Orissa super cyclone in 1999. Amphan developed as a low pressure area on 13 May 2020, over the south-eastern BoB. With favourable atmospheric conditions, warm SST and low vertical wind shear, it intensified further. On 16 May 
2020 it was designated as a depression (BOB 01). Moving northwards, the depression organized into a cyclonic storm named Amphan. On 17 May 2020, Amphan intensified further into a severe cyclonic storm, with winds from $140 \mathrm{~km} / \mathrm{h}(85 \mathrm{mph})$ at $12: 00$ UTC to $215 \mathrm{~km} / \mathrm{h}$ (130 mph) in $18.00 \mathrm{UTC}$, equivalent to a category-4 hurricane on the Saffir-Simpson scale. Figure 1 shows the track of the cyclone over BOB. This pre-monsoon cyclone created a huge catastrophe in West Bengal and Odisha as it had a landfall at Bakkhali on 20 May 2020. Amphan not only devastated property, infrastructure and resources, it also caused loss of human lives and cattle. Estimated losses due to Amphan are more than US\$ 13 billion.

\section{Data used}

\section{Satellite data}

Daily averaged SST derived from Indian geostationary satellite INSAT-3D at a spatial resolution of $4 \mathrm{~km}$ was used. The satellite has an imager with six channels in the visible and infrared range that makes acquisitions every $30 \mathrm{~min}$ and SST was generated operationally using the algorithm given by Mathur et al. ${ }^{10}$. Daily averaged net short wave radiation (SWR) derived from INSAT-3Dderived SWR was utilized in the study. The net surface SWR over tropical oceans was estimated using high temporal (half-hourly) estimates of outgoing longwave radiation (OLR) from geostationary satellites ${ }^{11}$. Both these products are available at near real time from the Meteorological and Oceanographic Satellite Data Archival Centre (MOSDAC) web portal www.mosdac.gov.in. The daily SST and SWR were analysed to determine the mean SST and SWR for the full month of April and 1-12 May 2019 and 2020. This was done to examine the ocean conditions that prevailed prior to the formation of Amphan to analyse how these were different from conditions of 2019.

The sea surface salinity (SSS) measurements from SMAP have been utilized in this study. A monthly product from the Remote Sensing System (RSS) has been used here, which is provided at $25 \mathrm{~km}$ spatial resolution. (https://podaac-tools.jpl.nasa.gov/drive/files/allData/smap/ L3/RSS/V4/8day_running/SCI/2020).

Daily optimum interpolation sea surface temperature (OISST) anomalies at $25 \mathrm{~km}$ spatial resolution generated by NOAA have also been used in this study ${ }^{12}$. This is an analysed product generated by combining observations from different platforms (satellites, both microwave and infrared sensors, in situ observations including, ships, buoys, and Argo floats) on a regular global grid (https:// psl.noaa.gov/data/gridded/data.noaa.oisst.v2.highres.html).

Global ocean multi-mission altimeter gridded sea surface heights (SSHs) and derived variables are currently available from the European Copernicus Marine Monitor- ing Service Environment (CMEMS). The product is a merged field of SSH combining the observations from Jason-3, Sentinel-3A, HY-2A, Saral/AltiKa, Cryosat-2, Jason-2, Jason-1, T/P, ENVISAT, GFO, ERS1/2 (ref. 13). The sea-level anomaly (SLA) is computed after removing long term mean (20 years) $\mathrm{SSH}$ from the original data. Weekly average SLA has been analysed to examine the SLA conditions prior to and during the formation of Amphan.

Analysed sea surface wind vectors from SCATSAT-I are available in near real time at a spatial resolution of $25 \mathrm{~km}$ (refs 14, 15). Currently, we use the daily analysed wind available from www.mosdac.gov.in. The time series of wind speed and its curl for the entire BoB have been analysed to observe the formation of Amphan.

\section{In situ observations}

From the network of Indian Ocean OMNI buoy system ${ }^{9}$, BD13 mooring was close to the track of the cyclone, which had recorded met-ocean parameters without much data gap. At this location $\left(87^{\circ} \mathrm{E}, 14^{\circ} \mathrm{N}\right)$, therefore, the variability of air/sea temperature, OLR, sea-level pressure and wind speed have been studied in detail. Observations of two RAMA (Research Moored Array for AfricanAsian-Australian Prediction) buoys ${ }^{16}$ located at $90^{\circ} \mathrm{E}$ along $12^{\circ}$ and $15^{\circ} \mathrm{N}$ respectively, have also been utilized for analysing the temperature and salinity.

\section{Results and discussion}

A deep depression over BoB, viz. BOB1 was declared as a cyclonic storm by India Meteorological Department (IMD) on 16 May 2020 and named as Amphan. Being a

INSAT-3D VISIBLE BAND IMAGE 18MAY2020 0230Z

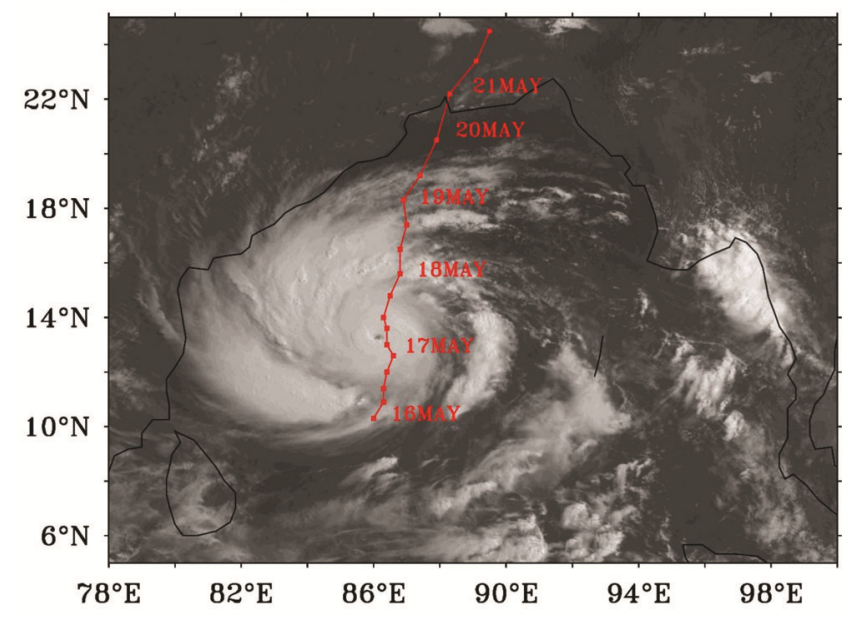

Figure 1. INSAT-3D image of cyclone Amphan on 18 May 2020 at $023 \mathrm{Z}$ with the track overlaid on it. 

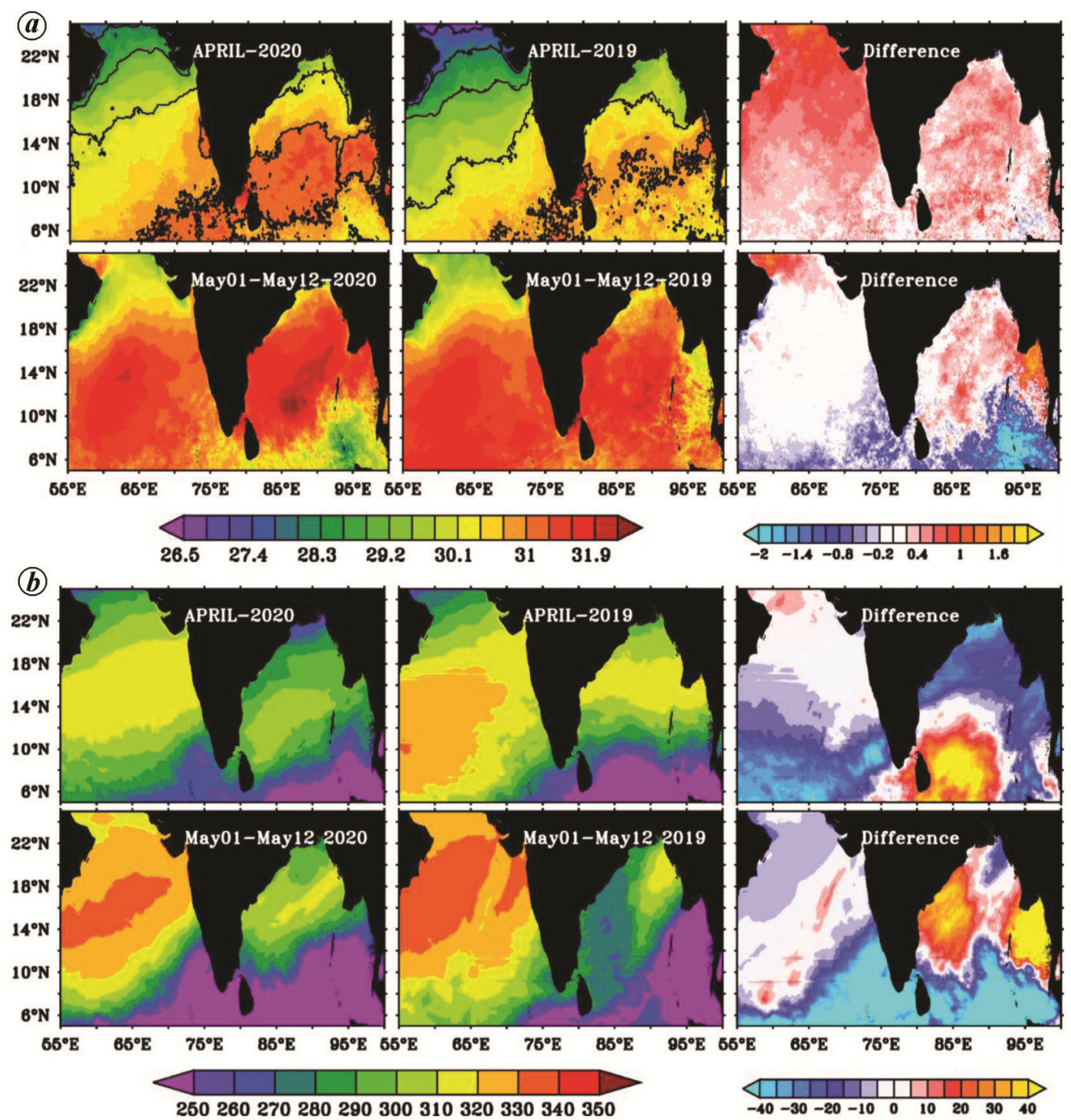

Figure 2. (a) The INSAT-3D sea surface temperature, $\left(\mathrm{SST} ;{ }^{\circ} \mathrm{C}\right)$ and $(\boldsymbol{b})$ shortwave radiation $\left(\mathrm{W} / \mathrm{m}^{2}\right)$ for 2019 and 2020. The right most panels show the differences between 2020 and 2019.

pre-monsoon storm it is certain that Amphan gained the advantage of very warm oceans that provided energy to it. In order to analyse the kind of background energy that was available to the cyclone, SST and SWR from INSAT-3D were analysed. Figure $2 a$ shows the average SST and SWR observed in April 2020 and 2019 respectively. Similar plots for the period averaged over 1-12 May 2020 are also shown. When compared to 2019, central BoB was significantly warmer in 2020. This is clearly seen in the difference plots, and the warming in 2020 with respect to 2019 is roughly between $0.5^{\circ}$ and $0.9^{\circ} \mathrm{C}$. The plots of incoming SWR at the surface for April (Figure $2 b$ ), clearly show that compared to 2019 , the southern BoB received more solar insolation in 2020 compared to 2019. During 1-12 May the positive differences in net SWR were observed in the entire south and central Bay region. These figures clearly indicate that $\mathrm{BoB}$ received more insolation, which may have resulted in extra warming of the ocean surface during 2020.

Figure 2 represents the oceanic conditions of 2020 with respect to 2019 . Hence it would be imperative to consider the oceanic conditions with respect to long-term climatological mean. Figure 3 shows the monthly OISST anomalies for March and April 2020. It can be clearly seen that the positive SST anomalies which were present in the southwestern BoB during March 2020, further got spread and strengthened during April 2020. The cooler anomalies $\left(\sim 0.4^{\circ}-1^{\circ} \mathrm{C}\right)$ during March 2020 in central and northern BoB subsided and the ocean became warmer by almost $1.5^{\circ} \mathrm{C}$ in April 2020 . This clearly indicates that April was unusually warm compared to the climatological values.

Next we looked at SLA, which is a proxy to the upper ocean heat content ${ }^{17}$. Figure 4 shows anticyclonic eddies (representative of warm core) in the entire BoB, except 
for the western part. This shows the averaged (1-16 May 2020) SLA distribution marked in contours, OISST anomalies at the background along with the Amphan track overlaid on it. The intensity of Amphan is shown by the colours used in the dots. High (positive) Positive SLA anomalies are known to help in cyclone intensification $^{18,19}$. It is clearly seen that the positive SST anomalies shown in the background coincide with the warm core eddies with positive SLA $(\sim 20 \mathrm{~cm})$ indicative of higher heat content in the region. This could have possibly resulted in the intensification of Amphan to super cyclone category in a short span of time.

Figure 5 shows time sequence images of wind vectors obtained from SCATSAT-I. On 15 May 2020, one can observe the cyclone vortex centred around $87^{\circ} \mathrm{E}$ and $9^{\circ} \mathrm{N}$ in the SCATSAT-I analysed winds. The cyclone moved northward and the wind speed continuously increased until 18 May, when maximum wind speed of around $28 \mathrm{~m} / \mathrm{s}$ was recorded by SCATSAT-I. This product also reveals the eye region characterized by very low wind speed. On 19 May 2020 the cyclone moved further north towards the coast, albeit with a reduced wind speed compared to that on 18 May 2020. Finally, the cyclone made a land fall on 20 May. The sequence of events of cyclone strengthening and landfall is well captured by the SCATSAT- 1 .

One of the Indian Ocean moorings (BD13) was in close vicinity of this cyclone track and continuously provided three-hourly measurements of air/sea temperature, sea level pressure and wind speed ${ }^{9}$. These observations helped analyse the air-sea interaction mechanisms that took place pre- and post-Amphan. These processes are interesting as latent and sensible heat fluxes and their interactions with ocean and atmosphere often help depressions to grow into a cyclone ${ }^{20}$. Figure $6 a$ shows the variation of air and ocean temperature measured by the buoy. Figure $6 b$ shows the corresponding relative humidity. We also checked the downwelling LWR from RAMA buoy located at $15^{\circ} \mathrm{N}$ and $90^{\circ} \mathrm{E}$ (Figure not shown; RAMA buoy at this location being close to BD13 has been considered in the analysis). The measured LWR essentially represents the way atmosphere radiates heat back to the ocean. As discussed earlier the ocean being heated radiates the heat, and this eventually gets absorbed in the atmosphere. This increases air temperature under calm conditions. As the air near the ocean is warm and humidity is high, the downwelling LWR will increase. Under low wind speed condition (between 0 and $2.5 \mathrm{~m} / \mathrm{s}$ seen in Figure $6 c$ ) during the initial phase of May 2020 (from May 3 to 12 May 2020), it is expected that LWR will also show increasing trend. During 4 to 12 May 2020 air temperature was in the range $30^{\circ}-31^{\circ} \mathrm{C}$, implying a steady heat supply from ocean to the atmosphere. This eventually caused the atmosphere to warm up and a drop in sea-level pressure was noticed from 11 May 2020 onwards that was associated with gradual increase in wind speed. LWR from RAMA buoy also showed a sharp increase in LWR values from 14 to till 17 May 2020 (RAMA buoy reported LWR till 17 May 2020). The relative humidity reached $100 \%$ by $14-15$ May 2020 , which caused increase in the downwelling LWR. This suggests that there is intense heating of the entire atmospheric

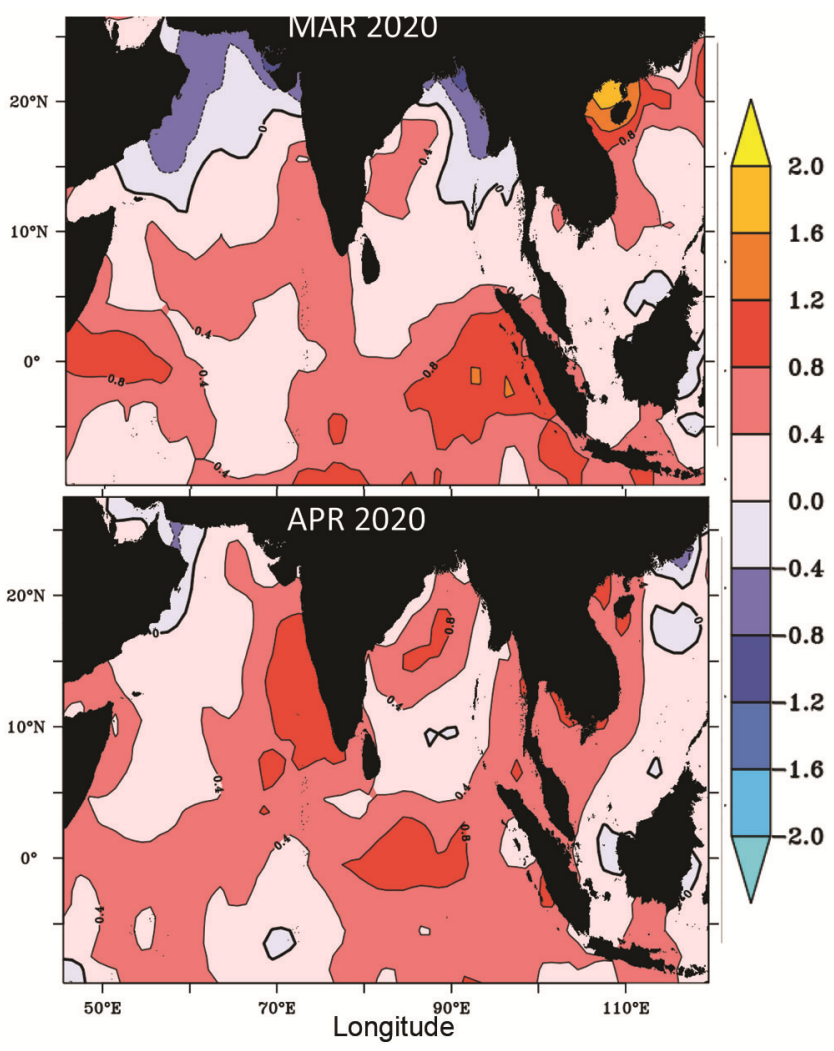

Figure 3. Mean monthly distribution of optimal interpolation SST $\left({ }^{\circ} \mathrm{C}\right)$ anomalies for (top panel) March and (bottom panel April 2020.

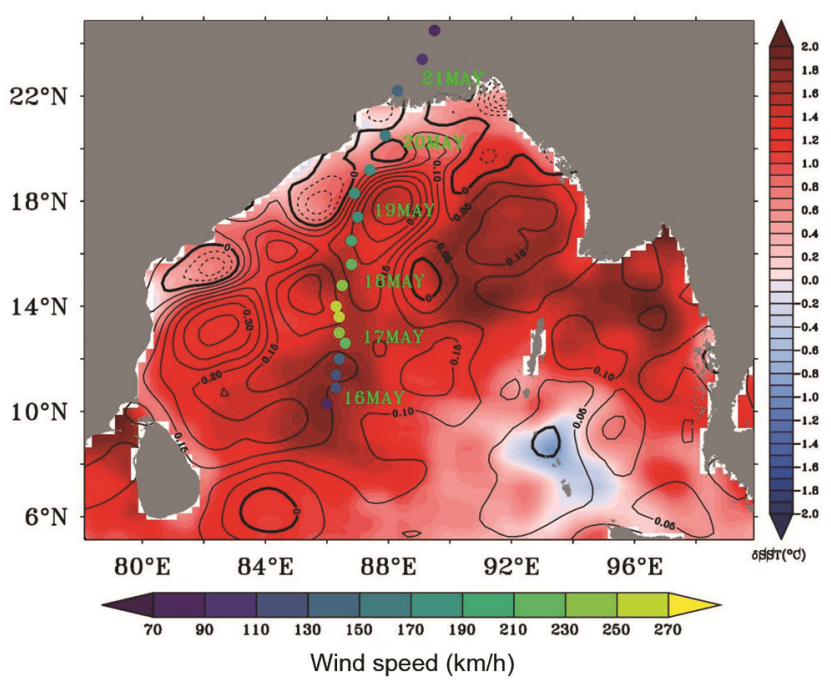

Figure 4. Background OISST anomaly (shaded) overlaid with sealevel anomalies (black contours) averaged for the period 1-16 May 2020. Colour dots represent cyclone wind intensity $(\mathrm{km} / \mathrm{h})$ over the track. 

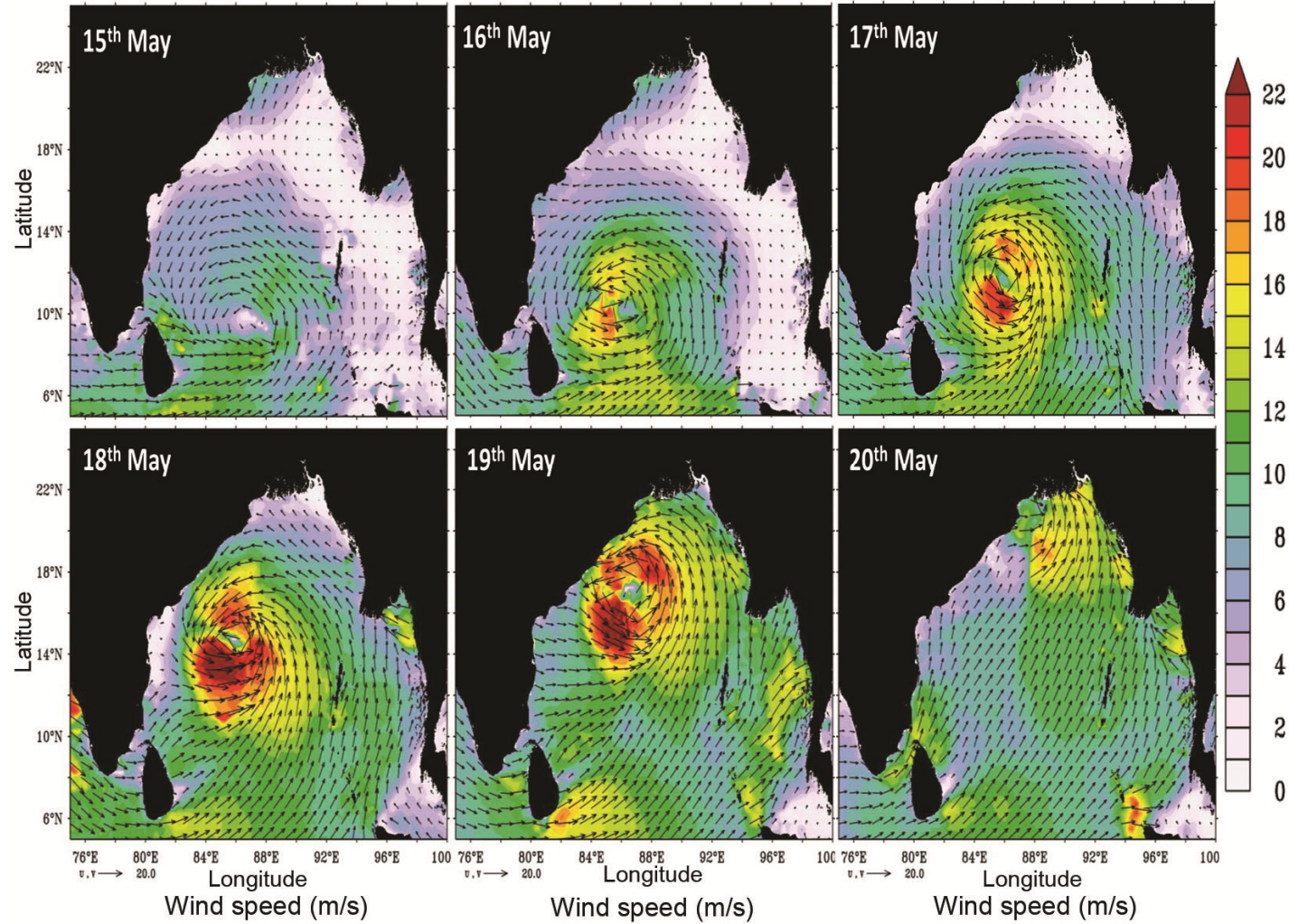

Figure 5. Time sequence of sea surface winds (m/s) observed from SCATSAT-I during cyclone Amphan.
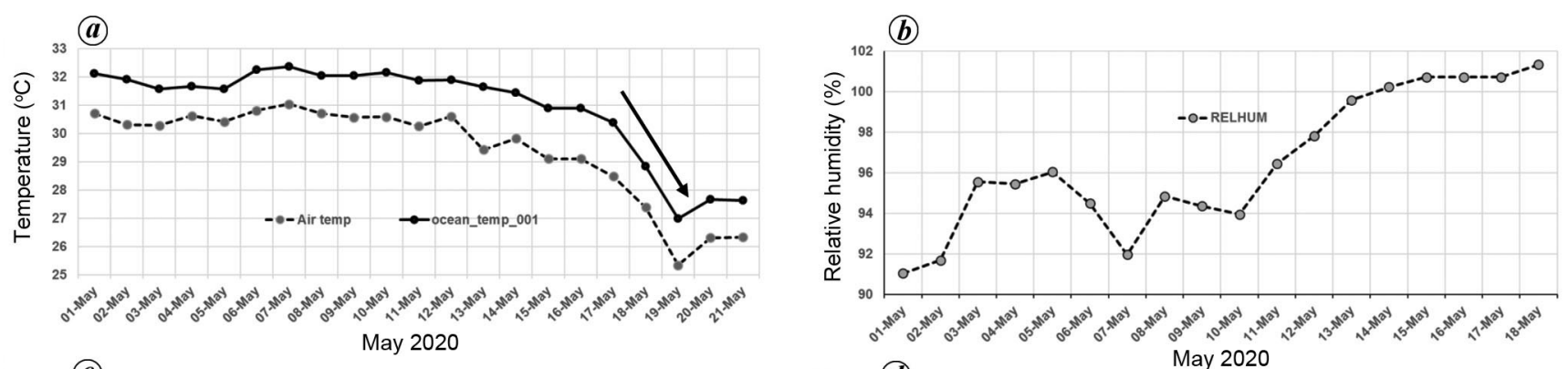

(c)

May 2020
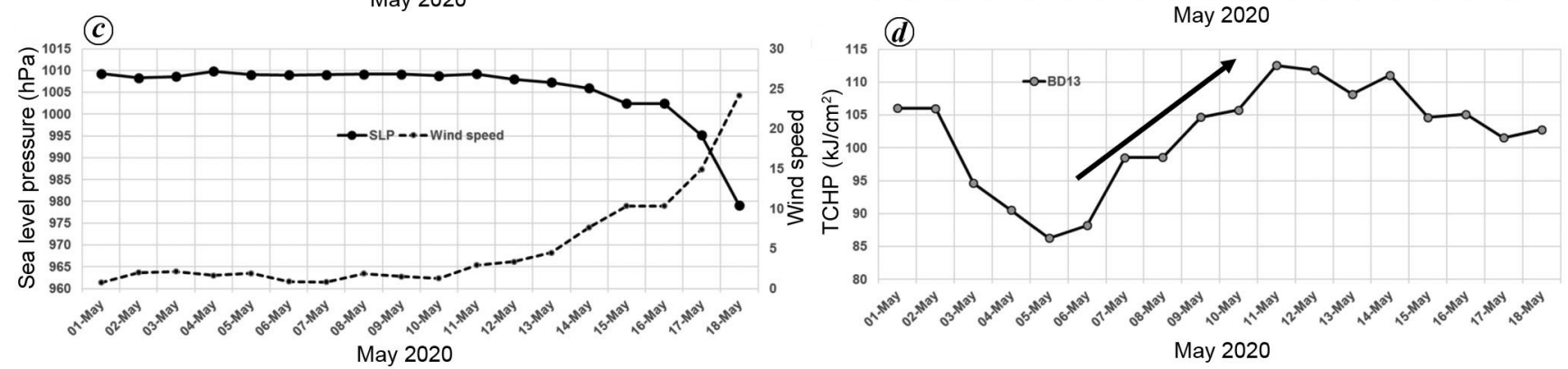

Figure 6. Variability of different parameters at the BD13 buoy location. (a) Time series of daily sea surface and air temperature $\left({ }^{\circ} \mathrm{C}\right)$; black arrow shows cooling of surface water post-cyclone. (b) Relative humidity (\%), (c) sea-level pressure (hPa) and wind speed (m/s). (d) Hourly tropical cyclone heat potential $\left(\mathrm{KJ} / \mathrm{cm}^{2}\right)$; black arrow shows heat build-up in the pre-cyclone phase.

column, which aids in the formation of cyclonic structure. Considering at the time series of tropical cyclone heat potential (TCHP), computed from buoy observations of sub surface temperature following Ali et al. ${ }^{18}$, one can see that the heat potential started building up from 5 May 2020 at BD13 buoy location (Figure $6 d$ ).

After the passage of Amphan, SST decreased due to wind mixing of the oceans. Buoy observations confirm 


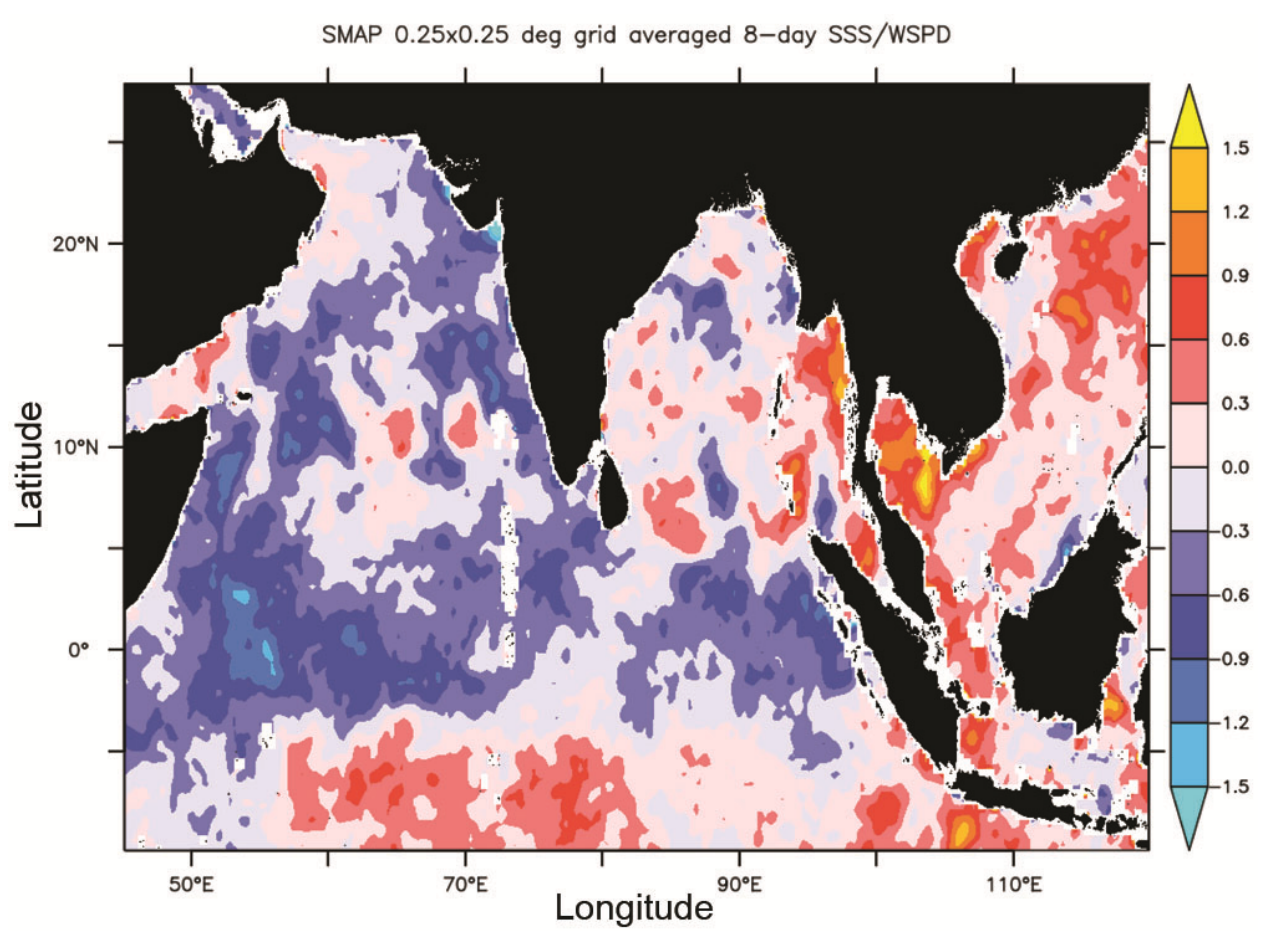

Figure 7. SMAP sea surface salinity anomaly (psu) between 15 April and 15 May 2020.

this as there is a drop in SST from a peak of $32^{\circ} \mathrm{C}$ observed on 10 May 2020 to around $27.5^{\circ} \mathrm{C}$ on 19 May $2020\left(>4^{\circ} \mathrm{C}\right.$ drop) at the BD13 location (Figure $6 a$ ). Correspondingly, there is a drop in air temperature during the same period. RAMA buoy located at $12^{\circ} \mathrm{N}$ and $15^{\circ} \mathrm{N}$ along $90^{\circ} \mathrm{E}$ also reported a similar cooling of almost $2.7^{\circ} \mathrm{C}$ post the passage of Amphan (figure not shown). Such a large cooling of the ocean occurred due to wind mixing induced by the cyclone. It is noteworthy here to understand that the salinity of BOB between April and May 2020 was almost 0.6 PSU more than its climatological mean (as reported from RAMA mooring at $15^{\circ} \mathrm{N}$, $90^{\circ} \mathrm{E}$ ). Similar signatures of higher salinity were also observed in the SMAP data (averaged between 15 April and 15 May), indicating that this period of 2020 was more saltier compared to climatology. Figure 7 depicts the SSS anomaly measured from SMAP. Higher salinity could lead to weaker stratification and therefore less resistance towards wind-induced. Hence, pronounced mixing occurred during Amphan that resulted in a large drop in the surface temperature of the ocean.

\section{Conclusion}

The category-5 TC Amphan formed over the south-eastern BoB caused extensive devastation in West Bengal and Odisha, India, some parts of Sri Lanka and Bangladesh. The present study shows that the intensity of this cyclone to super cyclone category could be attributed to the anomalous warming complemented by the presence of warm core eddies in the south and central BoB. Satellite observations clearly show that the central Bay was warmer compared to the climatological mean. This warming along with the positive SLA resulted in positive TCHP anomalies. At a local scale, using the buoy observations it was observed that under low wind speed conditions in the initial phase of May, the warm oceans heated the atmosphere, which resulted in the steady enhancement of LWR from the atmosphere to the ocean. This was associated with a drop in mean sea-level pressure and steady rise in wind speed from 13 May 2020 onwards. The observed wind speed from the SCATSAT-1 scatterometer also endorses a similar timeline observed over a large spatial area. Hence, apart from the crucial atmospheric conditions traditionally considered as important, one must also consider the ocean and associated air-sea interaction processes that take place prior to cyclogenesis.

1. Kalsi, S. R., Orissa super cyclone - a synopsis. Mausam, 2006, 57(1), 1-20.

2. Lin, I. I., Chen, C. H., Pun, I. F., Liu, W. T. and Wu, C. C., Warm ocean anomaly, air sea fluxes, and the rapid intensification of tropical cyclone Nargis (2008). Geophys. Res. Lett., 2009, 36, L03817; doi:10.1029/2008GL035815.

3. Shay, L. K., Goni, G. J. and Black, P. G., Effects of a warm oceanic feature on hurricane. Opal. Mon. Weather Rev., 2000, 128(5), $366-1383$.

4. Wu, M. C., Chang, W. L. and Leung, W. M., Impacts of El niñosouthern oscillation events on tropical cyclone landfalling activity in the western North Pacific. J. Climate, 2003, 17(6), 1419-1428.

5. McPhaden, M. J., Ocean-atmosphere interactions during cyclone Nargis. Eos, Trans. Am. Geophys. Union, 2009, 90(7), 53-60. 
6. Bhowmick. S. A., Agarwal. N., Ali. M. M., Kishtawal. C. M. and Sharma. R., Role of ocean heat content in boosting postmonsoon tropical storms over Bay of Bengal during La-Niña events. Climate Dyn., 2019, 52, 7225-7234.

7. Girishkumar, M. S., Thanga Prakash, V. P. and Ravichandran, M., Influence of pacific decadal oscillation on the relationship between ENSO and tropical cyclone activity in the Bay of Bengal during October-December. Climate Dyn., 2015, 44, 3469-3479.

8. Felton, C. S., Subrahmaniyam, B. and Murthy, V. S. N., ENSOmodulated cyclogenesis over the Bay of Bengal. J. Climate, 2013, 26, 9806-9817.

9. Venkatesan, R., Shamji, V. R., Latha, G., Mathew, S., Rao, R. R., Arul Muthiah, M. and Atmanand, M. A., New in situ ocean subsurface time series measurements from OMNI buoy network in the Bay of Bengal. Curr. Sci., 2013 104(9), 1166-1177.

10. Mathur, A., Srinivasan, I., Gohil, B. S., Sarkar, A. and Agarwal, V. K., Development of sea surface temperature retrieval algorithm for INSAT-3D. In Remote Sensing and Modeling of the Atmosphere, Oceans, and Interactions, International Society for Optics and Photonics, SPIE Conference, Goa, December 2006, 6404, 64040E.

11. Shahi, N. R., Thapliyal, P. K., Sharma, R., Pal, P. K. and Sarkar, A., Estimation of net surface shortwave radiation over the tropical Indian Ocean using geostationary satellite observations: algorithm and validation. JGR: Oceans, 2011, 116(C9), C09031.

12. Reynolds, R. W., Impact of Mount Pinatubo aerosols on satellite derived sea surface temperature. J. Climate, 1993, 6, 768-774.

13. SSALTO Handbook Reference: (M)SLA and (M)ADT near-real time and delayed time products, CLS-DOS-NT-06-034 Nomenclature: SALP-MU-P-EA-21065-CLS, 2011

14. Kumar, R. et al., Post launch calibration-validation and data quality evaluation of SCATSAT-1 data. Curr. Sci., 2019, 117(6), 973-982.
15. Bhowmick, S. A. et al., An assessment of the performance of ISRO's SCASTAT-1 scatterometer. Curr. Sci., 2019, 117(6), 960972.

16. McPhaden, M. J. et al., RAMA: The research moored array for African-Asian-Australian monsoon analysis and prediction. $B A M S, 2009,90(4), 459-480$.

17. Ali, M. M., Goni, G. J. and Jayaraman, V., Satellite-derived Ocean heat content improves cyclone predictions: utilization of satellite-derived Oceanic heat content for cyclone studies. EOS, Trans. Am. Geophys. Union, 91(43), 396-396.

18. Ali, M. M., Jagadeesh, P. S. V. and Jain, S., Effects of eddies on Bay of Bengal cyclone intensity. EOS Trans. Am. Geophys. Union, 2007, 88, 93-95.

19. Ali, M. M., Sinha, P., Jain, S. and Mohanty, U. C., Impact of sea surface height anomalies on cyclone track. Nature Preced., 2007; doi:10.1038/npre.2007.1001.1.

20. Gao, S., Jia, S., Wan, Y., Li, T., Zhai, S. and Shen, X., The role of latent heat flux in tropical cyclogenesis over the Western North Pacific: comparison of developing versus non-developing disturbances. JMSE, 2019; doi:10.3390/jmse7020028.

ACKNOWLEDGEMENTS. We thank the Directors of Space Applications Centre (SAC; ISRO) Ahmedabad and National Institute of Ocean Technology (NIOT) Chennai for their support and encouragement. We also thank Dr Raj Kumar (SAC) and Dr C. M. Kishtawal (SAC) for guidance. R.S., R.V., C.A.P. and K.N.N. thank the Ministry of Earth Sciences, Government of India, for providing financial support. The effort of NIOT technical team for maintenance of moored buoys is acknowledged.

Received 26 June 2020; revised accepted 26 August 2020

doi: $10.18520 / \mathrm{cs} / \mathrm{v} 119 / \mathrm{i} 9 / 1510-1516$ 